Gut, 1979, 20, 977-982

\title{
Pepsin 5 in gastric juice: determination and relationship to the alkali-stable peptic activity
}

\author{
V. WALKER AND W. H. TAYLOR \\ From the Department of Chemical Pathology, Royal Liverpool Hospital, Liverpool
}

SUMmaRY Pure human pepsins 1 and 3 are inactivated by incubation at $\mathrm{pH} 7 \cdot 1-7 \cdot 3$ for 30 minutes, losing $90 \%$ or more of activity. Pepsin 5 is alkali-stable, retaining $100 \%$ of activity. Mixtures of pure pepsins 1 and/or 3 with pepsin 5 were found to have greater alkali-stable activity than predicted. Two published methods for determining the alkali-stable fraction of the peptic activity of gastric juice gave, respectively, in our hands values of $45 \cdot 4-80.0 \%$ and $27 \cdot 5-43.9 \%$ of the total activity. These values seemed too high to be attributable only to pepsin 5 in gastric juice, as agar gel electrophoresis shows pepsin 3 to have the principal activity. Electrophoretograms of alkaline incubated gastric juice revealed that large amounts of pepsin 3 retained activity as well as pepsin 5, and a proteolytic zone ' 4 ' appeared between them. Alkali inactivation thus does not allow the estimation of pepsin 5 individually in gastric juice. Pepstatin, at a final concentration of 100 to $170 \mathrm{pmol} / \mathrm{ml}$, may be used to estimate pepsin 5 in gastric juice and gave values of 18.0 to $27.6 \%$ of the total peptic activity. Pepsin 5 , in gastric juice and in mixtures of pepsins, appears to protect pepsin 3 from alkaline-inactivation, and to a lesser extent from pepstatin inhibition.

Now that the multiplicity of the pepsins of man is established (see review by Taylor, 1962), the need to estimate the pepsins individually in gastric juice is apparent (Taylor, 1970; Walker, 1976; Walker and Taylor, 1976). Turner et al. (1967) observed that the 'pepsin 1' of Seijffers et al. (1964) was. stable at $\mathrm{pH} 7.0$ and showed only a slow loss of activity between $\mathrm{pH} 7.0$ and $\mathrm{pH} 7.5$, whereas pepsins IIA, IIB, and III showed a rapid loss of proteolytic activity at $\mathrm{pH} 7 \cdot 0$. Turner et al. (1967) therefore developed a technique for estimating 'pepsin 1' in gastric juice, based on its alkali-stability at $\mathrm{pH} 7 \cdot 24$ 7.26. Seijffers and Tkatch (1970) reported an alternative method based on the same principle, but using weak alkali and an incubating $\mathrm{pH}$ of 7.1.

Because the study of the pepsins has been confused by the use of different systems of nomenclature, Etherington and Taylor (1967) proposed that the pepsins be numbered in order of decreasing mobility to the anode on agar gel electrophoresis. They found subsequently (Etherington and Taylor, 1969) that the 'pepsin 1' of Seijffers et al. (1964) was mainly their pepsin 5 , the slowest migrating pepsin, as was the 'gastricsin' of Richmond et al. (1958). Roberts and Taylor (1973) and Roberts (1975) demonstrated the stability of an electrophoretically homogeneous preparation of pepsin 5 to alkali, and Received for publication 16 May 1979 the alkali-lability of preparations of the more electronegative pepsins, pepsin 1 and 3 .

The primary aim of the present investigation was to determine whether the technique of alkaliinactivation is a reliable way of estimating pepsin 5 individually in a gastric juice. As the shortcomings of the method became apparent, preliminary experiments were undertaken to determine whether use of the acid proteinase inhibitor, pepstatin (Umezawa et al., 1970) might provide a better alternative. Aoyagi et al. (1971) had found that, whereas human 'pepsin' prepared from human gastric juice by the method of Richmond et al. (1958) is readily inhibited by pepstatin, 'gastricsin' is approximately 100 times more resistant to inhibition that is pepsin. Roberts (1975) found that pepstatin readily inhibited preparations of the electronegative pepsins, pepsins 1 and 3, and to a similar extent, whereas pepsin 5 was approximately 40 times less sensitive to inhibition.

\section{Methods}

GASTRIC JUICE

Gastric juice was collected over 15 minute intervals by aspiration via nasogastric tube, basally and after pentagastrin injection $(6 \mu \mathrm{g} / \mathrm{kg}$ body weight) or intravenous insulin injection $(0.15$ units $/ \mathrm{kg}$ body weight). 
HUMAN PEPSINS

Electrophoretically homogeneous preparations of human pepsins 1,3 , and 5 and a mixture of pepsins 3 and 5 were kindly donated by Dr N. B. Roberts, who prepared them by chromatography of pooled human gastric juice on DEAE (diethylaminoethyl) cellulose using chloride gradient elution (Etherington and Taylor, 1969; Roberts and Taylor, 1978).

\section{PEPSTATIN}

Pepstatin (iso-valeryl-L-valyl-L-valyl-4 amino-3 hydroxy-6-methylheptanoyl-L-alanyl-4 amino3 hydroxy- 6 methyl heptanoic acid) was kindly donated as the sodium salt by Dr K. Goto and Dr H. Umezawa of the Banyu Pharmaceutical Co., Tokyo, Japan.

ESTIMATION OF PROTEOLYTIC ACTIVITY The method was that of Anson and Mirsky (1932), as modified by Hanley et al. (1966) and further by Etherington and Taylor (1969). One 'pepsin unit' is arbitrarily defined as that amount of peptic activity which releases tyrosine and tyrosine-containing peptides from bovine haemoglobin, colorimetrically equivalent to $1 \mathrm{mg}$ standard tyrosine under the conditions of assay.

\section{ALKALI INACTIVATION}

Method of Turner et al. (1967)

By preliminary assay, a dilution of pepsin solution or gastric juice was determined with activity in the linear part of the standard proteolytic activity curve for swine pepsin. Solutions of twice this strength were prepared in $\mathbf{0 . 1} \mathrm{M}$ acetate buffer, $\mathrm{pH} \mathrm{5.0.} \mathrm{Half}$ was mixed with an equal volume of $0.001 \mathrm{M}$ acetate buffer $\mathrm{pH} 5.0$ (control). The $\mathrm{pH}$ of the remainder was increased to $7 \cdot 12-7 \cdot 20$ by mixing with an equal volume of $0.1 \mathrm{M}$ phosphate buffer, pH 7.80 (test). In some instances 1 or 2 drops of $0.25 \mathrm{M}$ sodium hydroxide were needed to adjust the $\mathrm{pH}$ to within this range and an equal volume of $\mathrm{pH} 5.0$ buffer was then always added to the control tube. The samples were mixed well and left at room temperature $\left(21^{\circ}-23^{\circ} \mathrm{C}\right)$. At intervals from one to 48 minutes after addition of alkaline buffer, $0.1 \mathrm{ml}$ of test and control (each in duplicate) was removed and assayed for peptic activity.

This procedure differed slightly from that originally described, in that: (a) preliminary dialysis of the gastric juice samples was omitted, as this was not a procedure used in measuring the total peptic activity of the samples, with which the results were ultimately to be related; (b) the temperature of alkaline incubation was room temperature $\left(21^{\circ}\right.$ to $\left.23^{\circ} \mathrm{C}\right)$ and not $25^{\circ} \mathrm{C}$ as described by Turner et al.).
Seijffers and Tkatch (1970)

Gastric juice was diluted 1 in 5 with $0 \cdot 1 \mathrm{M}$ acetate buffer, $\mathrm{pH} 5 \cdot 3$, and this mixture was further diluted (1 in 10) with $0.02 \mathrm{M}$ phosphate/0.01 M citric acid buffer, pH 7.8, to give a final pH of $7 \cdot 10$ to $7 \cdot 30$. The tubes were covered and left at room temperature $\left(21^{\circ}-23^{\circ} \mathrm{C}\right)$. At exactly 90,105 , and 120 minutes after addition of alkali, $0.1 \mathrm{ml}$ was removed and assayed for peptic activity in duplicate. The mean residualthat is, alkali-stable-activity was calculated. The 'control' activity of each gastric juice-that is, not inactivated-was estimated by diluting each gastric juice first 1 in 5 in $0.1 \mathrm{M}$ acetate buffer $\mathrm{pH} 5 \cdot 3$, and further diluting this mixture (1 in 10) in $0.02 \mathrm{M}$ phosphate/0.01 $\mathrm{M}$ citric acid buffer pH 7.0, with rapid mixing, giving a final dilution of 1 in 50, and a $\mathrm{pH}$ of 6.5 to 6.6 . Immediately after mixing, $0.1 \mathrm{ml}$ was assayed in duplicate for peptic activity.

\section{ALKALI INACTIVATION FOLLOWED BY}

AGAR GEL ELECTROPHORESIS

Gastric juice and pepsins were incubated for 30 minutes at room temperature at $\mathrm{pH} 7 \cdot 10-7 \cdot 20$ using the method of Turner et al., described above, but with higher concentrations of enzyme solution. Zymograms of the alkaline-preincubated pepsin solutions and of the 'native' pepsin solutions, diluted to the same strength in $0.001 \mathrm{M}$ hydrochloric acid, were obtained by agar gel electrophoresis at $\mathrm{pH} \mathrm{5.0,}$ using the technique of Etherington and Taylor (1969) with the following small changes: $15 \mathrm{~g} / 1$ Ionagar no. 2 was used to prepare the gels; electrophoresis was for two hours 10 minutes, and a human globin substrate concentration of $3.3 \mathrm{~g} / 1$ in $\mathrm{pH} 2.0$ buffer was used to demonstrate zones of proteolytic activity.

\section{INHIBITION OF HUMAN PEPSINS AND} PEPTIC ACTIVITY OF GASTRIC JUICE BY PEPSTATIN

$50 \mu$ of each of a series of solutions of pepstatin containing 0.001-25 $\mu \mathrm{g}$ pepstatin $/ \mathrm{ml}(0.0014-35.26$ $\mathrm{nmol} / \mathrm{l}$ ) in $0.05 \mathrm{M}$ acetate buffer $\mathrm{pH} 4.0$ was added respectively to tubes containing $1.9 \mathrm{ml}$ bovine haemoglobin substrate $\mathrm{pH} 2.0 ; 50 \mu \mathrm{l}$ of buffer without pepstatin was added to a further, control tube. After mixing, the tubes were incubated at $37^{\circ} \mathrm{C}$ for five to 10 minutes in a water bath, $0.1 \mathrm{ml}$ diluted pepsin solution or gastric juice was added, and proteolytic activity was determined by the modified Anson and Mirsky procedure.

\section{Results}

SENSITIVITY OF INDIVIDUAL PEPSINS TO ALKALI

Using the method of Turner et al., pepsins 1 and 3 were both readily inactivated by preincubation at 
pH $7 \cdot 10-7 \cdot 30$, losing $90 \%$ or more of activity. Pepsin 5 was alkali-stable, retaining $100 \%$ of activity (Fig. 1). These results confirm the findings of Roberts and Taylor (1973). A mixture of pepsins 3 and 5 , on the other hand, retained $63 \%$ of the initial activity, despite the preponderance of pepsin 3 solutions, a 'predicted value' for the alkali-stable activity of each pepsin mixture was calculated. In Table 1, the 'predicted activities' of the mixtures are compared with the alkali-stable activities actually observed. In the control assays, the pepsin mixtures had activities close to the predicted. On alkalisation,

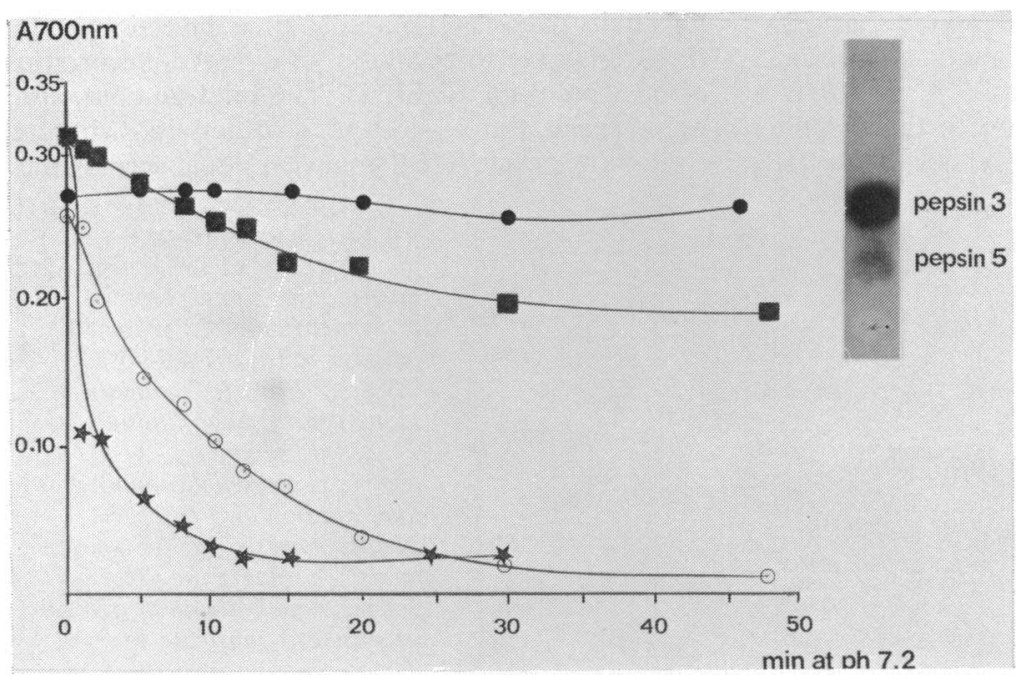

Fig. 1 Sensitivity of human pepsins to alkali. Solutions of pepsins 1, 3, 5 and a mixture of pepsins 3 and 5 were preincubated at $\mathrm{pH}$ 7.10-7.30 for 48 minutes at room temperature $\left(21^{\circ}-22^{\circ} \mathrm{C}\right)$. Samples were removed at intervals and assayed with bovine haemoglobin ( $p H$ 2.0) for 30 minutes at $37^{\circ} \mathrm{C}$ for residual peptic activity $(A 700 \mathrm{~nm})$ *-* pepsin 1 . O_O pepsin 3 . -D pepsin $3+5$ mixture. -Opepsin 5. An agar gel electrophoretogram of the initial $3+5$ mixture is shown. in the mixture (see accompanying electrophoretogram).

\section{SENSITIVITY OF MIXTURES OF PEPSINS}

\section{1, 3, AND 5 TO ALKALI}

Solutions of the individual pepsins and mixtures of these solutions were (1) preincubated at $\mathrm{pH} \mathbf{7 \cdot 2 0}$ for 30 minutes at room temperature $\left(23^{\circ} \mathrm{C}\right)$, using the method of Turner et al., and residual peptic activity was estimated, and (2) preincubated for 30 minutes at $\mathrm{pH} 5.3$ before assay (controls). Knowing the proportions by volume of the solutions of pepsins 1,3 , and 5, respectively, comprising each mixture and the alkali-stable activity of the component pepsin the mixture of pepsins 1 and 3 behaved almost as predicted, with loss of $89 \%$ of peptic activity. Mixtures containing pepsin 5, however, all had more residual activity after alkaline preincubation than predicted. It is clear from Table 1 that the alkalistable peptic activity is a poor guide to the proportion of pepsin 5 present in the mixture.

\section{ALKALI-INACTIVATION OF PEPSINS IN GASTRIC JUICE}

Fifteen minute gastric juice samples collected during the course of pentagastrin tests were each analysed for total and alkali-stable peptic activity by the modified method of Turner et al. (15 samples from

Table 1 Effects of alkaline preincubation* and of pepstatin on mixtures of pepsins 1, 3, and 5 (pepstatin concentration: $35.3 \mathrm{pmol} / \mathrm{ml}$ )

\begin{tabular}{|c|c|c|c|c|c|c|}
\hline \multirow{2}{*}{$\begin{array}{l}\text { Pepsin or pepsin } \\
\text { mixture (proportions } \\
\text { by volume) }\end{array}$} & \multicolumn{2}{|c|}{$\begin{array}{l}\text { Control activity } \\
\text { (units } / \mathrm{ml})\end{array}$} & \multicolumn{2}{|c|}{$\begin{array}{l}\text { Alkali-stable activity } \\
\text { (units } / \mathrm{ml})\end{array}$} & \multicolumn{2}{|c|}{$\begin{array}{l}\text { Pepstatin-resistant activity } \\
\text { (units/ml) }\end{array}$} \\
\hline & Observed & Predicted & Observed & Predicted & Observed & Predicted \\
\hline 1 & 0.52 & & 0.02 & & $0 \cdot 10$ & \\
\hline 3 & 0.64 & & 0.06 & & $0 \cdot 12$ & \\
\hline 5 & 0.64 & & 0.66 & & 0.62 & \\
\hline $1+3(1: 1)$ & 0.54 & 0.58 & 0.06 & 0.04 & 0.08 & $0 \cdot 11$ \\
\hline $3+5(1: 1)$ & 0.65 & 0.64 & 0.50 & $0 \cdot 37$ & 0.42 & 0.37 \\
\hline $1+3+5(1: 1: 1)$ & 0.64 & 0.60 & 0.46 & $0 \cdot 25$ & 0.38 & 0.28 \\
\hline $1+3+5(1: 3: 2)$ & 0.69 & 0.62 & 0.48 & $0 \cdot 26$ & 0.41 & 0.29 \\
\hline $1+3+5(1: 4: 1)$ & 0.65 & 0.62 & 0.31 & $0 \cdot 15$ & 0.31 & 0.21 \\
\hline
\end{tabular}

* Method of Turner et al. (1967) with 30 minute preincubation. 
two tests) or by that of Seijffers and Tkatch (six samples from a third test).

The alkali-stable activity ranged from $45.4 \%$ to $80.0 \%$ of the total activity by the modified method of Turner et al., and from $27 \cdot 5-43.9 \%$ of the total activity by the method of Seijffers and Tkatch.

Electrophoretograms of gastric juice samples incubated at $\mathrm{pH} 7 \cdot 10-7 \cdot 18$ for 30 minutes at $22^{\circ} \mathrm{C}$ (Fig. 2) revealed that large amounts of pepsin 3 retained activity as well as pepsin 5, and that a proteolytic zone ' 4 ' appeared between them. Under these conditions this may simply be due to partially and the resistance of pepsin 5 to pepstatin are shown in Table 1, thus confirming the observations of Roberts (1975).

INHIBITION OF MIXTURES OF PEPSINS 1,3 , AND 5, BY PEPSTATIN

The mixed pepsin solutions tested for alkalisensitivity were at the same time investigated for their resistance to pepstatin, at a final concentration of $35.3 \mathrm{pmol} / \mathrm{ml}$ (Table 1 ). The mixture containing only pepsins 1 and 3 lost $85 \%$ of activity. Mixtures containing pepsin 5 had greater residual activity than

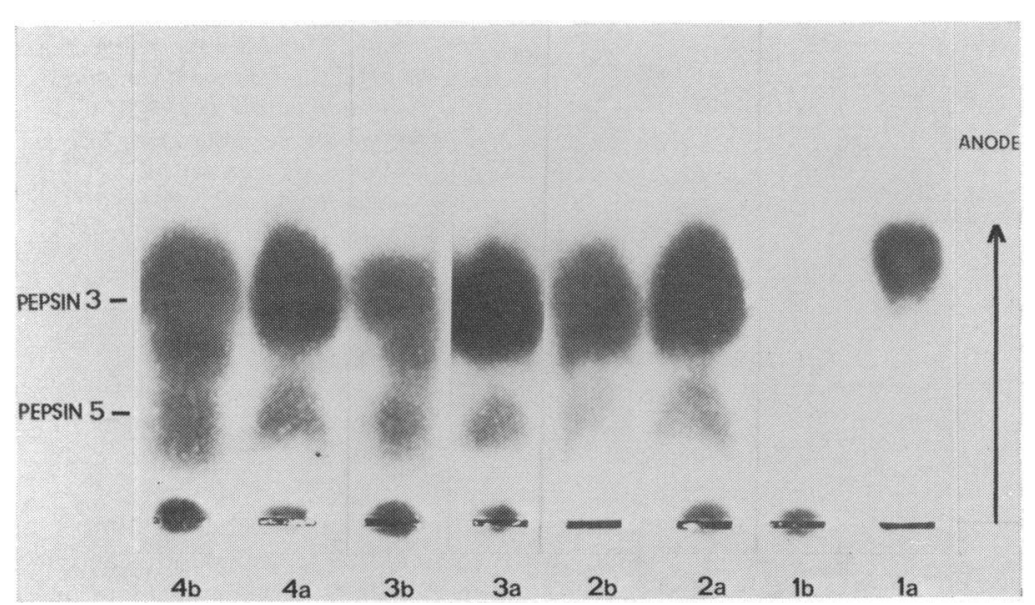

Fig. 2 Agar gel electrophoretograms of swine pepsin and gastric juice samples after preincubation at $22^{\circ} \mathrm{C}$ for 30 minutes at (a) pH 4.75-5.10; (b) $\mathrm{pH}$ 7.10-7.18. Sample 1swine pepsin, final dilution $17 \mu \mathrm{g} / \mathrm{ml}$; samples 2, 3, and 4, gastric juice samples applied at a final dilution of 1 in 14 . Electrophoresis was for two hours 10 minutes at $\mathrm{pH} 5.0$. $3.3 \mathrm{~g} / \mathrm{l}$ human globin at $\mathrm{pH} 2.0$ was used as substrate to demonstrate zones of proteolytic activity. NB: Pepsin 1 was not present in this patient. A proteolytic zone 4 is seen in electrophoretograms $3 b$ and $4 b$. denatured pepsin 3. Alternatively, it could represent a pepsin/inhibitor complex which migrates in a similar position on electrophoresis (Etherington and Taylor, 1969).

INHIBITION OF INDIVIDUAL PEPSINS BY PEPSTATIN

The sensitivities of preparations of pepsins 1 and 3 predicted, although the differences between the observed and predicted values were smaller than was found for the alkali-preincubated samples.

INHIBITION OF PEPTIC ACTIVITY OF GASTRIC JUICE BY PEPSTATIN

Pepsins 1 and 3 were not completely inhibited by pepstatin at a final concentration of $35.3 \mathrm{pmol} / \mathrm{ml}$

Table 2 Effect of pepstatin on peptic activity of gastric juice collected during insulin/pentagastrin test

\begin{tabular}{|c|c|c|c|}
\hline \multirow[t]{2}{*}{ Gastric juice sample } & \multirow{2}{*}{$\begin{array}{l}\text { Total peptic activity } \\
\text { (no inhibitor) } \\
\text { (units } / \mathrm{ml} \text { ) }\end{array}$} & \multicolumn{2}{|c|}{ Pepstatin-resistant activity } \\
\hline & & (units/ml) & (as per cent of total activity) \\
\hline 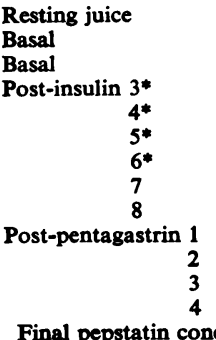 & $\begin{array}{l}48 \cdot 4 \\
9 \cdot 6 \\
20 \cdot 0 \\
122 \cdot 4 \\
112 \cdot 0 \\
100 \cdot 0 \\
78 \cdot 4 \\
59 \cdot 2 \\
54 \cdot 4 \\
36 \cdot 8 \\
40 \cdot 8 \\
30 \cdot 8 \\
34 \cdot 0 \\
\text { Nas } 176 \cdot 3 \mathrm{pmol} / \mathrm{ml} .\end{array}$ & $\begin{array}{r}13 \cdot 2 \\
2 \cdot 4 \\
3 \cdot 6 \\
28 \cdot 8 \\
28 \cdot 0 \\
20 \cdot 0 \\
21 \cdot 6 \\
15 \cdot 2 \\
12 \cdot 8 \\
8 \cdot 8 \\
9 \cdot 6 \\
8 \cdot 0 \\
8 \cdot 0\end{array}$ & $\begin{array}{l}27 \cdot 3 \\
25 \cdot 0 \\
18 \cdot 0 \\
23 \cdot 5 \\
25 \cdot 0 \\
20 \cdot 0 \\
27 \cdot 6 \\
25 \cdot 7 \\
23 \cdot 5 \\
23 \cdot 9 \\
23 \cdot 5 \\
26 \cdot 0 \\
23 \cdot 5\end{array}$ \\
\hline
\end{tabular}

* Samples diluted 1 in 200 for assay; all others diluted 1 in 100. 
(see above). Using a higher final concentration $(176.3 \mathrm{pmol} / \mathrm{ml})$, pepsin 1 retained $6.0 \%$, pepsin 3 , $18 \%$, and pepsin $5,86 \%$ of initial activity. The peptic activities of 1315 -minute gastric juice samples, collected during a combined insulin-pentagastrin test, were estimated with and without pepstatin at $176.3 \mathrm{pmol} / \mathrm{ml}$ final concentration (Table 2). The pepstatin-resistant activity represented $18 \cdot 0-27 \cdot 6 \%$ of the combined peptic activity, and this proportion was remarkably constant for widely differing 'control' peptic activities of the samples.

\section{Discussion}

From the results presented, it appears unlikely that either of the two methods used for alkali inactivation measured the activity of pepsin 5 individually in gastric juice samples, for the following reasons: firstly, electrophoretograms of gastric juice samples which had been preincubated at $\mathrm{pH} 7.10-7.18$ for 30 minutes showed that, in addition to pepsin 5 , relatively large amounts of pepsin 3 , and of a pepsin migrating in the position of zone 4 of Etherington and Taylor, retained activity. Secondly, mixtures of solutions of the lindividual pepsins, which included pepsin 5, had higher alkali-stable activities than was predicted from the alkali-stable activities of the constituent solutions. The explanation for this observation is not known, although the possibility that there may have been some protective interaction between the pepsin molecules cannot be excluded. Such an interaction might also be anticipated between the pepsins of gastric juice, which is a pepsin 5-containing mixture. Thirdly, the values obtained for the percentage of total peptic activity of gastric juice which is alkali-stable $-45.4 \%$ to $80.0 \%$, using the modified method of Turner et al., and $27.5 \%$ to $43.9 \%$ using the method of Seijffers and Tkatch seem too high to be attributable only to pepsin 5 (Table 3). Tang et al. (1959) by subjecting gastric juice to chromotography on Amberlite, estimated the ratio of 'pepsin' to 'gastricsin' to be approximately 4:1. Etherington and Taylor (1969), however, have since shown that 'gastricsin' prepared in this way, although containing mainly pepsin 5 , contains some pepsin 3 also. On visual inspection of agar gel electrophoretograms, pepsin 5 usually, subjectively, accounts for $20-25 \%$ of the total proteolytic activity, although the proportion varies between samples. By semi-quantifying pepsin 5 from agar gels in terms of swine pepsin equivalent, and comparing this value with the total peptic activity of gastric juice, Walker (1976) found that pepsin 5 accounted for $4.0-17.0 \%$ of the total activity. This range is possibly a little low, as results from two different methods of assay were compared in the calculation.

Turner et al. did not quote values for the percentages of peptic activity of gastric juice which was alkali-stable, although in one figure shown in their paper, a gastric juice sample has approximately $33 \%$ of residual activity after alkaline preincubation. Seijffers and Tkatch found ratios for the alkali-labile to alkali-stable peptic activity in 20 gastric juice samples of 1.47 to 4.25 , so that the percentage of alkali-stable activity was $19.1 \%$ to $40.5 \%$. However, 14 of the samples had ratios of 2.03 or lower, giving alkali-stable activity between $33.3 \%$ and $40.5 \%$, which would seem too high to be attributable only to pepsin 5. Although these workers found close agreement between the alkali-stable: alkali-labile peptic activity ratios and the ratios of the activities of their 'pepsin 1' to the summated activities of all the other pepsins eluted during chromatography of gastric juice on DEAE cellulose, 'pepsin 1' prepared in this way was found to be a mixture of pepsins 3 and 5 (nomenclature of Etherington and Taylor, 1967) when examined by agar gel electrophoresis, and it is moreover unlikely that the most electronegative of the pepsins (pepsins 1 and 2) were eluted from the column (Etherington and Taylor, 1969).

From the experiments with pepstatin, it was concluded that the use of this inhibitor may provide a better means of measuring pepsin 5 selectively in gastric juice. No preliminary dialysis of the gastric juice samples is necessary and the total peptic activity and pepstatin-resistant activity may be estimated by the same procedure. Clearly the concentration of inhibitor used is of critical im-

Table 3 Determinations of pepsin 5 ('gastricsin' and 'Seijffers' pepsin 1) as percentage of total peptic activity of gastric juice

\begin{tabular}{lll}
\hline Method & Authors & Per cent of total peptic activity \\
\hline Chromatography on Amberlite & Tang et al. (1959) & Approx. 20 \\
Alkali-inactivation: method of Turner et al. & Turner et al. (1967) & $33 \cdot 0$ (approx.; one sample only) \\
Alkali-inactivation: method of Seijffers and Tkatch & Walker (1976) & $45 \cdot 4-80 \cdot 0$ \\
& Seijffers and Tkatch (1970) & $19 \cdot 1-40 \cdot 5$ \\
APDT hydrolysis* & Walker (1976) & $27 \cdot 5-43 \cdot 9$ \\
Agar gel electrophoresis & Chiang et al. (1966) & Basal secretion: 24.8-41.9; \\
Resistance to pepstatin & Walker (1976) & $4 \cdot 0-17 \cdot 0$ (approx.) \\
& Walker (1976) & $18 \cdot 0-27 \cdot 6$
\end{tabular}

*Acetyl phenylalanyl L-di-iodotyrosine. 


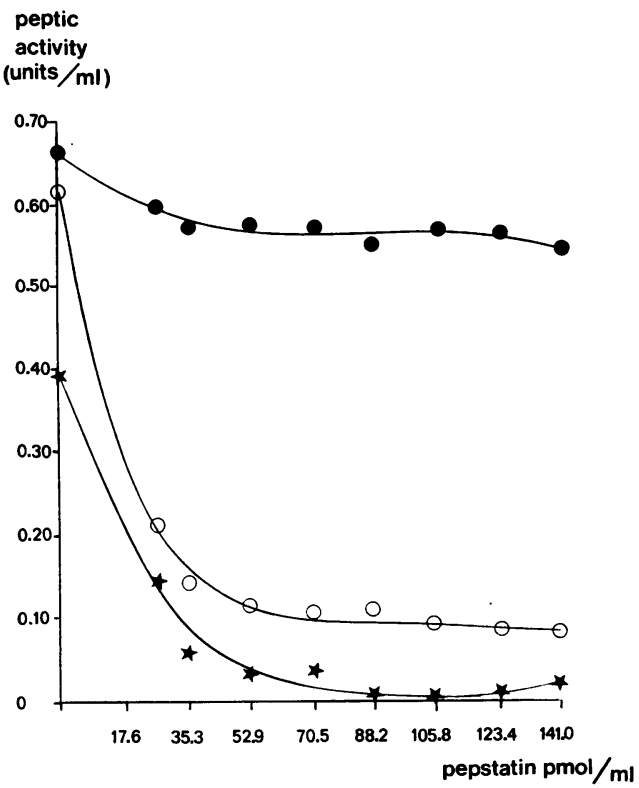

Fig. 3 Inhibition of pepsins 1, 3, and 5 by pepstatin. Final concentrations of pepstatin are given. *-* pepsin 1 . O-O pepsin 3 . - - pepsin 5. (after Roberts, 1975).

portance, if pepsins 1 and 3 are to be inhibited maximally and pepsin 5 is to retain full activity. A final pepstatin concentration of $176.3 \mathrm{pmol} / \mathrm{ml}$ almost met the requirements; from the data of Fig. 3 it would seem that final concentrations from about $100 \mathrm{pmol} / \mathrm{ml}$ upwards would give a similar result; pepsin 1 is almost completely inhibited at these levels, pepsin 3 retains about $15 \%$ of its activity, and pepsin 5 loses about $15 \%$ so that the latter two effects tend to balance out each other.

The protective action of pepsin 5 on pepsin 3 during exposure to alkaline conditions is a barrier to our analytical techniques, but is, nevertheless, a remarkable biochemical phenomenon which is at present unexplained. Physiologically, the pepsins of gastric juice meet an alkaline environment as soon as they enter the duodenum. It is widely believed that their proteolytic action then ceases because they are progressively destroyed and because they are in any case inactive above $\mathrm{pH}$ 4.0. Our observations (for 30 minutes at $21^{\circ}-23^{\circ} \mathrm{C}$ ) suggest that destruction may not be as complete as might be imagined but it is still difficult to conceive of any further physiological, or pathological, role for the pepsins, as the hydrogen ion concentration in the intestine is unfavourable.

\section{References}

Anson, M. L., and Mirsky, A. E. (1932). Estimation of pepsin with haemoglobin. Journal of General Physiology, 16, 59-63.

Aoyagi, T., Kunimoto, S., Morishima, H, Takeuchi, T., and Umezawa, H. (1971). Effect of pepstatin on acid proteases. Journal of Antibiotics, 24, 687-694.

Chaing, L., Sanchez-Chiang, L., Wolf, S., and Tang, J. (1966). The separate determination of human pepsin and gastricsin. Proceedings of the Society of Experimental Biology and Medicine, 122, 700-704.

Etherington, D. J., and Taylor, W. H. (1967). Nomenclature of the pepsins. Nature, 216, 279-280.

Etherington, D. J., and Taylor, W. H. (1969). The pepsins of normal human gastric juice. Biochemical Journal, 113, 663-668.

Hanley, W. B., Boyer, S. H., and Naughton, M. A. (1966). Electrophoretic and functional heterogeneity of pepsinogen in several species. Nature, 209, 996-1002.

Richmond, V., Tang, J., Wolf, S., Trucco, R. E., and Caputto, R., (1958). Chromatographic isolation of gastricsin, the proteolytic enzyme from gastric juice with pH optimum 3.2. Biochimica et Biophysica Acta, 29, 453-454.

Roberts, N. B. (1975). The Human Gastric Proteinases: Studies on their Isolation and Characterisation. Thesis: University of Liverpool.

Roberts, N. B., and Taylor, W. H. (1973). The inactivation by carbenoxolone of individual human pepsinogens and pepsins. Clinical Science and Molecular Medicine, 45, 213-224.

Roberts, N. B., and Taylor, W. H. (1978). The preparation and purification of individual human pepsins by using diethylaminoethyl-cellulose. Biochemical Journal, 169, 607-615.

Seijffers, M. J., Segal, H. L., and Miller, L. L. (1964). Chromatographic separation of pepsins from human gastric juice. American Journal of Physiology, 207, 8-12.

Seijffers, M. J., and Tkatch, R. (1970). Assay of two pepsin fractions in human gastric juice by alkali inactivation. Gastroenterology, 59, 528-533.

Tang, J., Wolf, S., Caputto, R., and Trucco, R. E. (1959). Isolation and crystallization of gastricsin from human gastric juice. Journal of Biological Chemistry, 234, 1174-1178.

Taylor, W. H. (1962). Proteinases of the stomach in health and disease. Physiological Reviews, 42, 519-553.

Taylor, W. H. (1970). Pepsins of patients with peptic ulcer. Nature, 227, 76-77.

Turner, M. D., Tuxill, J. L., Miller, L. L., and Segal, H. L. (1967). Measurement of pepsin 1 (gastricsin) in human gastric juice. Gastroenterology, 53, 905-911.

Umezawa, H., Aoyagi, T., Morishima, H., Matsuzaki, M., Hamada, M., and Takeuchi, T. (1970). Pepstatin, a new pepsin inhibitor produced by actinomycetes. Journal of Antibiotics, 23, 259-262.

Walker, V. (1976). Aspects of the Pathophysiology of the Pepsins. Thesis: University of Liverpool.

Walker, V., and Taylor, W. H. (1976). Pepsin 1 secretion in peptic ulcer and in stress (Abstract). Clinical Science and Molecular Medicine, 51, 14p. 